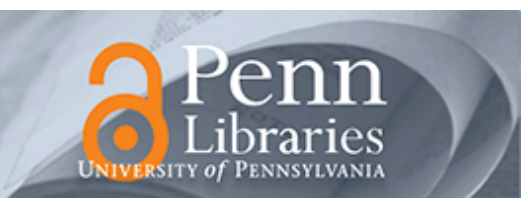

University of Pennsylvania ScholarlyCommons

January 2007

\title{
Rapid Assessment of Existing HIV Prevention Programming in a Community Mental Health Center
}

\author{
Phyllis L. Solomon \\ University of Pennsylvania, solomonp@sp2.upenn.edu \\ Julie A. Tennille \\ University of Pennsylvania \\ David Lipsitt \\ Massachusetts School of Professional Psychology \\ Ellen Plumb \\ University of Pennsylvania \\ David Metzger \\ University of Pennsylvania, dsm@mail.med.upenn.edu
}

See next page for additional authors

Follow this and additional works at: https://repository.upenn.edu/spp_papers

\section{Recommended Citation}

Solomon, P. L., Tennille, J. A., Lipsitt, D., Plumb, E., Metzger, D., \& Blank, M. (2007). Rapid Assessment of Existing HIV Prevention Programming in a Community Mental Health Center. Retrieved from

https://repository.upenn.edu/spp_papers/56

Postprint version. Published in Journal of Prevention \& Intervention in the Community, Volume 33, Issue 1-2, 2007, pages 137-151.

Publisher URL: http://dx.doi.org/10.1300/J005v33n01_11

This paper is posted at ScholarlyCommons. https://repository.upenn.edu/spp_papers/56

For more information, please contact repository@pobox.upenn.edu. 


\title{
Rapid Assessment of Existing HIV Prevention Programming in a Community Mental Health Center
}

\author{
Abstract \\ In preparation for implementation of a comprehensive HIV prevention program in a Community Mental \\ Health Center for persons with mental illness who are also abusing substances, a rapid assessment \\ procedure (RAP) of existing prevention services that may have developed in the setting over time was \\ undertaken at baseline. In addition to an ecological assessment of the availability of HIV-related \\ information that was available on-site, in-depth interviews and focus groups were conducted with Center \\ administrators, direct-care staff, and mental health consumers. Results indicated that responses \\ regarding available services differed depending upon type of respondent, with administration reporting \\ greater availability of preventive programs and educational materials than did direct-care staff or mental \\ health consumers themselves. But overall, formalized training on HIV prevention by case managers is \\ extremely rare. Case managers felt that other providers, such as doctors or nurses, were more \\ appropriate to deliver an HIV prevention intervention.
}

\section{Keywords}

ecological assessment, mental health services, serious mental illness, substance abuse

\section{Comments}

Postprint version. Published in Journal of Prevention \& Intervention in the Community, Volume 33, Issue 1-2, 2007, pages 137-151.

Publisher URL: http://dx.doi.org/10.1300/J005v33n01_11

\section{Author(s)}

Phyllis L. Solomon, Julie A. Tennille, David Lipsitt, Ellen Plumb, David Metzger, and Michael Blank 


\title{
Rapid Assessment of Existing HIV Prevention Programming in a Community Mental Health Center
}

\author{
Phyllis L. Solomon, PhD \\ Julie A. Tennille, MSW \\ David Lipsitt, BA \\ Ellen Plumb, BA \\ David Metzger, $\mathrm{PhD}$ \\ Michael B. Blank, PhD \\ University of Pennsylvania
}

Phyllis Solomon, PhD, is a Professor of Social Work and Professor of Social Work in Psychiatry at the University of Pennsylvania, 3535 Market Street, Philadelphia, PA, 19104; email:

solomonp@ssw.upenn.edu; Phone: 215-898-5533.

Julie Tennille, MSW is a Senior Project Coordinator in the Center for Mental Health Policy and Services Research, University of Pennsylvania, 3535 Market Street, Philadelphia, PA 19104; email:

Julie.tennille@gmail.com; Phone: 215-349-8486.

Ellen Plumb, BA is a Research Assistant in the Center for Mental Health Policy and Services Research, University of Pennsylvania, 3535 Market Street, Philadelphia, PA 19104; email: ellenplumb@yahoo.com; Phone: 215-349-8486.

David Lipsitt is a Doctoral Candidate at the Massachusetts School of Professional Psychology, 221 Rivermoor Street, Boston, MA 02132; email: dlipsitt@gmail.com; Phone: 617-529-4999.

Michael Blank, PhD is an Assistant Professor of Psychology in Psychiatry, Assistant Professor of Nursing, and Senior Fellow at the Leonard Davis Institute of Health Economics, University of Pennsylvania, 3535 Market Street, Philadelphia, PA 19104; email: mblank2@mail.med.upenn.edu; Phone: 215-349-8488.

This research was supported in part by the National Institute on Drug Abuse (RO1-DA15627) and the National Institute for Nursing Research (RO1- NR008851).

Address correspondence to: Phyllis Solomon, PhD, Professor of Social Work and Professor of Social Work in Psychiatry, University of Pennsylvania, 3535 Market Street, Philadelphia, PA, 19104; email:

solomonp@ssw.upenn.edu; Phone: 215-898-5533 
SUMMARY. In preparation for implementation of a comprehensive HIV prevention program in a Community Mental Health Center for persons with mental illness who are also abusing substances, a rapid assessment procedure (RAP) of existing prevention services that may have developed in the setting over time was undertaken at baseline. In addition to an ecological assessment of the availability of HIV-related information that was available on-site, in-depth interviews and focus groups were conducted with Center administrators, directcare staff, and mental health consumers. Results indicated that responses regarding available services differed depending upon type of respondent, with administration reporting greater availability of preventive programs and educational materials than did direct-care staff or mental health consumers themselves. But overall, formalized training on HIV prevention by case managers is extremely rare. Case managers felt that other providers, such as doctors or nurses, were more appropriate to deliver an HIV prevention intervention.

KEYWORDS. Ecological Assessment, Mental Health Services, Serious Mental Illness, Substance Abuse.

Rates of HIV infection among adults with severe psychiatric disorders are well above the rates in the general population (Blank, Mandell, Aiken, Hadley, 2002) and the cost of providing care for those with co-morbid HIV and serious mental illness is substantially higher than the combined costs of treating those with either a serious mental illness or HIV (Rothbard, Metreaux, \& Blank, 2003). Consequently, there is increasing concern regarding the transmission of HIV and other sexually transmitted infections (STI) among persons with severe mental illness (SMI). In particular, there is even greater concern for those with co-morbid substance abuse who tend to engage in more risky behaviors for contracting these diseases, and for whom infection rates further exceed those of their SMI peers. In recent years, the published literature has documented a few effective group educational interventions specifically designed for this population (e.g., Johnson-Masotti, Weinhardt, Pinkerton, Otto-Salaj, 2003; Kelly, 1997; Otto-Salaj, Kelly, Stevenson, et al, 2001; Otto-Salaj, Stevenson, Kelly, 1998). However, these educational prevention interventions have usually been implemented for research purposes under very well controlled conditions, as opposed to being incorporated into routine clinical care of community mental health services. Consequently, we know the effectiveness of researchled interventions, but not of provider-led interventions (Encandela, Korr, Hulton, Koeke, et al, 2003). Also, virtually all of these interventions have been group-oriented rather than individually-oriented. Given that many of this population do receive some services from community mental health agencies, mostly case management, these service contacts afford individual opportunities for educating them about prevention strategies for reducing risky sexual and drug related behaviors (Eisenberg \& Blank, 2004). Further, the American Psychiatric Association recommends that outpatient clinicians offer HIV risk 
reduction interventions as part of their regular practice (APA, 1998; Brunette, Mercer, Carlson, Rosenberg \& Lewis, 2000).

To address this gap, we designed a randomized trial of an HIV prevention intervention (PATH - Preventing Aids Through Health) to be delivered individually by case managers in a community mental health center to substance abusing adults with SMI. Prior to implementing the intervention, we undertook a Rapid Assessment Process (Beebe, 2001) to document the nature of HIV prevention activities that may have already been employed by case managers when serving their SMI consumers. At the conclusion of the randomized trial, we will conduct another rapid assessment to determine what changes have occurred in the service environment as a result of the intervention in order to document the diffusion of the innovation (Rogers, 1983). This report presents the results of this baseline assessment and is a qualitative assessment of how case managers in a large urban community mental health agency address educating SMI consumers regarding prevention of HIV/AIDS and other sexually transmitted diseases as well as the extent to which they address this issue at all.

The limited research that has been conducted on whether HIV prevention services are offered to this population by the public mental health system has generally found that it is rather rare, as "providers do not actively address HIV/STI issues in persons with SMI” (Brunette, et al, 2000, p. 348). Sullivan and her colleagues (1999) noted that some providers are reluctant to address HIV risks among their consumers due to perceived concerns regarding confidentiality. The public mental health system's lack of knowledge regarding their consumers' risk of HIV infections relieves this overburdened and underfunded service system of the responsibility of addressing what could be an extremely costly problem (Sullivan, et. al, 1999). Other barriers to addressing HIV prevention with this high risk population include outdated attitudes about the asexuality of the population, lack of knowledge and skills related to HIV issues and behavioral HIV risk reduction interventions, fears and anxiety about addressing the topic, discomfort in dealing with issues about consumer sexuality, lack of designated funding for such services, and a lower priority level than other pressing consumer safety and survival needs (Aruffo, Thompson, McDaniel, 1996; Brunette, et al, 2000; Carmen \& Brady, 1990; Grassi, 1996; Knox, 1989; Sullivan et al, 1999; McKinnon, Cournos, Herman, et al, 1999; Shernoff, 1988). Yet, another barrier that evolved from a focus group study was case managers were concerned that discussing sexual risk behaviors in a consumer's home or private place would be misinterpreted by the consumer (Encandela, et al, 2003).

Regardless of the potential resistance to the provision of prevention services for adults with SMI by public community mental health providers, there is clearly a need to offer more systematically such education. Case management provides a logical service choice for integration of HIV prevention interventions, as it targets those with SMI, particularly those most likely to engage in risky behaviors. It is also the dominant approach to serving this population (Weinhardt, Bickman \& Carey. 1999). In addition, the types of activities required for the provision of an HIV prevention intervention are consonant with those in which case managers are already engaged. Further, due to the longstanding relationships that evolve between many case managers and SMI consumers, they are well situated to assess risk, broach sexually explicit topics that are otherwise taboo and discomforting, titrate the intervention to counter individual risk factors, assess when information has been learned, and periodically reinforce learned information. 
In a recent comprehensive focus group study of mental health case management as a locus for dissemination of HIV prevention, Encandela and his colleagues (2003) found that case managers who participated in the study were very willing and interested in providing HIV-prevention interventions to their consumers. Also, they did not feel that assessing risk would overburden them, even when they had a full caseload. However, these case managers cautioned that HIV prevention services needed to be delivered within the context of the case management relationship. In other words, this service should be approached organically through the course of a conversation, rather than being forced on consumers in a systematic fashion. Furthermore, given the priorities of consumer needs, such as shelter and psychiatric stability, as well as the pressing demands on case managers' time, they felt that an HIV prevention intervention needed to be incorporated into their current practices, as opposed to being an additional service. In addition, case managers felt that this topic would be best addressed in a broad context, rather than specifically about HIV transmission. These case managers also believed that it was appropriate for them to conduct risk assessments, but with regard to education they felt others, such as therapists or health care providers would be better suited. Their role would be to link their consumers with these providers and other appropriate services.

Encandela et al. (2003) also assessed the extent and type of training for HIV prevention that the case managers received and found that case managers reported that they had received limited, if any, formal training on issues of HIV/AIDS and HIV prevention. Some claimed to have received none; others received a one-time basic information session.

\section{METHODS}

\section{Setting}

The community mental health agency where this study was undertaken is part of a hospital that serves the center of the city as well parts of the southern portion of the city. These areas are extremely diverse encompassing much of the revitalized center of the city as well as many seriously deprived neighborhoods. The catchment area served by the center is almost 100,000 people with $82 \%$ Caucasian, $18 \%$ minority, and $17 \%$ under the federal poverty level. Crime is especially high and there are a large number of institutional and social service agencies in the service area. This service area has over $50 \%$ of all homeless shelter beds in the city and a large number of residential programs for persons who are homeless as well as mentally ill consumers. The agency serves 350 consumers per day and 3800 adults a year. Thirty-five per cent of consumers served are African American. Over three-quarters of the consumers have a psychiatric diagnosis related to a serious mental illness (SMI), and fully two-thirds are dually diagnosed with substance abuse disorders.

The agency has three different case management programs. Resource Coordination (RC) is a combined broker- direct service case management program. Each of the case managers of RC serves on average 30 consumers. Intensive case management (ICM) does more direct service to consumers data collection who require more intensive supervision. ICM serves on average 17 consumers with much of the service delivered in 
the community where consumers live, work, and recreate. The ACCESS program serves SMI adults with multiple needs, including housing supports, as many of these consumers are or were homeless at one time. Caseload size for case managers in the ACCESS program is 8-9 persons.

\section{Rapid Assessment Process}

The methodology for this qualitative assessment employed a Rapid Assessment Process (RAP) which is defined by Beebe (2001) as "intensive, team-based qualitative inquiry using triangulation, iterative data analysis and additional to quickly develop a preliminary understanding of a situation from the insider's perspective” (p. xv- emphasis in the original). The team is recommended to have a diversity of perspectives and to have both insiders as well as outsiders of the phenomenon that is being assessed. RAP differs from traditional ethnography as it is always conducted by a team of at least two individuals, in terms of both data collection and data analysis. The intensive team approach is an alternative to the prolonged fieldwork required in ethnography (Beebe, 2001).

RAP is not defined by specific research techniques, but rather by the use of triangulation and iterative analysis. Triangulation refers to "use of data from different sources, the use of several different researchers, the use of multiple perspectives to interpret a single set of data, and the use of multiple methods to study a single problem" (Beebe, 2001, p. 19). In this study we employed both in-depth interviews and focus groups, using multiple perspectives to collect and analyze data, and as a means of validation. Initially we conducted interviews with representatives of all parties connected with the case management services, administrators, case managers, the agency nurse, and mental health consumers of the case management programs. These interviews were followed by two focus groups--one with case managers and the other with the consumers themselves. The purpose of the focus groups was to obtain additional data and to validate our themes from the in-depth interviews.

The team for this study was comprised of the Co-Principal Investigator of the project, a mental health services researcher and Ph.D. in social welfare (the first author), the Project Coordinator (a social worker and the second author), two research assistants (a bachelor's degree in psychology and the third author, and a bachelor's degree in anthropology and the fourth author), and the Principal Investigator (a community/clinical psychologist and the fifth author).

\section{Sampling, Data Collection, and Analysis}

Working with the administrator of the adult outpatient programs of the study site agency and the director of the ICM program, we selected the individuals to be asked to participate in the interviews and the focus groups. Participants were selected with the intention of roughly representing the demographics of the existing client base at the clinic, and to represent diversity regarding gender and ethnicity. For the interviews, we specified that we wanted at least one case manager from each program, and additional administrators from RC and ACCESS. Thus we interviewed two directors, 1 male black and 1 white male. In addition, we interviewed the one agency nurse who works with 
consumers from all programs in the agency, not just case management. For case managers, we interviewed two black males and one white female. Besides selecting consumers to be interviewed from amongst those receiving services from each of the three programs, additionally we specified that we wanted consumers who were sexually active or desired to become sexually active as an inclusion criterion. We conducted individual in-depth interviews with two black males and one white male. The consumer focus group was comprised of eight participants (2 black females, 4 black males, and 2 white males) and the case manager focus groups was comprised of five individuals (2 black females, 1 white female, and 2 black males).

The provider interviews started with a brief introduction, followed by a general icebreaker question about the activities that they engage in during the course of the day. The interview then focused on the kind of training that existed for consumers on the topics of HIV, blood borne infections, and substance abuse, including proper condom use and safe sex practices; whether this training should be done; and who should or should not be providing the training. Providers were then asked about the training they themselves received in these domains and whether they felt they needed the training. Finally, they were asked what kind of resources or materials they provide to consumers to reduce their risk of HIV. These included what type of training they received, whether training should be conducted, who should or should not receive training, and what kind of materials or information were provided. The consumers were asked parallel questions.

After each of the interviews, the research team assembled to discuss the content and extract themes. The outside members checked with the inside members about questions regarding what they thought they heard during the interviews. For example, one team member thought he had heard that consumers engage in prostitution and another thought she heard that consumers engaged in sex with prostitutes. Although both occur, we confirmed that in fact engaging in prostitution was the more frequent behavior.

After conducting the in-depth interviews, we continued to extract and develop themes based on reading the transcripts of the interviews. One of the team members (a research assistant) transcribed the tapes (all interviews and focus groups were taped except two interviews - one consumer refused and one time the tape recorder malfunctioned). Based on these transcribed interviews a synopsis was developed and checked for accuracy and omissions by all research team members. Using the synopsis, the research team collectively extrapolated a list of themes. The list of themes was used to inform the development of open-ended focus group questions. For the most part, the questions used in the focus groups were the same questions that were asked during the indepth interviews, with the exception of the phraseology of providing training to consumers. Instead of asking the focus group participants about HIV “training”, the participants were asked to comment on consumer-case manager discussions on the topic of HIV. These changes were made in response to concerns that arose during the in-depth interviews over the term "training". According to the in-depth interview participants, the word "training" suggested formalized educational intervention and there was concern that this interpretation may have limited the nature of responses to the in-depth interview questions. Consequently, the focus group participants responded to essentially the same questions as the in-depth interview participants, with exception of this slight wording modification. At the conclusion of the focus group, members were asked for their opinions concerning the accuracy of the list of themes developed and whether there was 
anything missing from the list. The entire process, from conducting the first interview to the groups and write-up of the final synopsis took one month, reflecting the utility of the RAP for these purposes.

\section{RESULTS}

As can be observed in Table 1, the four topical areas that emerged from the interviews and the focus groups were the way in which education regarding prevention of sexually transmitted infections and drug use was practiced by case managers, what these administrators and providers perceived as risk factors and non-risk factors, under what circumstances they discussed prevention topics, and the training that was received by case managers. Each of these topics will be discussed below.

\section{The Practice of Prevention Education by Case Managers}

Case managers reported that activities intended to educate consumers about prevention of sexually transmitted diseases were minimal and without formal training. It was left to the discretion of the individual case manager as to how he or she interacted with their consumers regarding these topics and each worker had a different approach. Some case managers were comfortable talking to their consumers about risk taking behaviors, while others were not. Some case managers would discuss a particular incident of inappropriate sexual behavior or some recurring behavior such as unprotected sex with the consumer. For example, as one case manager explained, "Many of our consumers engage in prostitution, and we will suggest safe sex methods. But because sex is such a touchy subject, a lot of consumers just do not discuss these topics, unless they have a complaint about a symptom. This will then provide an opportunity to engage the consumer in a discussion about preventive behaviors."

In contrast, administrators suggested that was training made available to case managers regarding HIV prevention and risk behaviors, and that prevention with consumers was indeed taking place at the agency. Administrators noted that they encourage staff to educate consumers, but "Consumers are not strong cognitively. They just want treatment and not education”. Further, one stated, "We're professionals that give advice on substance abuse. When we get into AIDS and blood-borne infections, we don't know what we're talking about and are less likely to go in there.” One of the administrators whom we interviewed was concerned that case mangers would not have the time to deliver an educational intervention on sexually transmitted infections. This person felt that there were many other higher priorities with which the case managers had to be concerned. They suggested that substance abuse is a topic with which case managers are more comfortable and have more training and resources available in this service domain. Case management services are designed to connect consumers with resources such as a public health center. Many felt other health professionals were better equipped to address topics relating to sexual behaviors than were they. One case manager stated, “I don't have expertise in this area, so I refer to the docs. We have a lot of resources to link our consumers to."

A case manager indicated that a lot of the consumers are positive for Hepatitis $C$, and many admit that they may have contracted Hepatitis $C$ from unprotected sex. Once 
case managers find out that a consumer is infected, they can have a discussion on HIV risk and the need to get tested. When someone gets diagnosed with HIV, case managers do get involved, making sure the consumer follows-up with medical appointments and continues with the full course of treatment. This may also trigger other consumers to request information and to begin to protect themselves from the disease.

It was also noted that education on these issues is not a priority. "We have the chronically homeless and we have a lot of consumers that do extended periods of time inpatient. We're pretty much focused on stabilizing their mental state - that's the priority - then we try to work on everything else." Or, as another case manager said "We don't have anything established to do it. I'd have to go through my supervisor and make arrangements. If we had a program in place it would make it so much easier. When you think of all the ongoing issues, sitting down and showing a consumer how to use a condom, it's not on the first to-do list. It's not that safe sex is not important, but just trying to get them stable mentally enough to be in one place to work with them, I think that's something that's generally overlooked."

Consumers also noted that case managers rarely ask about sexual activities, about having safety products for sexual activities, and getting tested. Some consumers noted that they received training on these topics from other programs and agencies and didn't need anything more as they were already knowledgeable. If consumers ask about getting examined or tested, case managers will schedule an appointment. One consumer noted that no education was done, "Nothing outside of always be safe and use protection when having sex."

\section{Perceived Risk Factors}

Training depends on the behavior of the individual consumer. If the consumer is known to engage in risky behaviors or in promiscuous behavior then conversations regarding education about prevention will surface more than with other consumers. The factors associated with risky behaviors that were identified included being male, using drugs particularly intravenous drugs, having multiple sex partners, engaging in sexually inappropriate behavior, engaging in prostitution, or having a new girlfriend or boyfriend. In addition, symptoms of HIV or another STI are other indicators that require immediate responses from case managers. One case manager stated, "More than likely training would be for someone who's already diagnosed.”

\section{Perceived Non-Risk Factors}

Consumers as well as staff felt that if consumers were not sexually active, there was no need to provide them with educational training on prevention and risk behaviors. Others thought that individuals who were elderly did not have a need for this type of training. Some felt that women were at less of a risk than men. Consumers felt that any training on these types of topics should be based on consumer choice.

\section{Circumstances Under which Not to Discuss These Issues}


There were circumstances under which providers felt that HIV prevention was inappropriate and other circumstances where they were not comfortable about discussing these topics. Some suggested that cross-gender pairing of the worker and the consumer may render conversations about sexual issues inappropriate. One case manager provided an example of a consumer who reported that she had been raped by a black man (he did not know if this was true or not), but the case manager felt that, as a black man himself, it was not an appropriate topic to discuss with her. Other workers noted that it was also inappropriate to discuss these topics when consumers were highly paranoid or in an unstable state. In addition, some case managers expressed concern that their relationships with their consumers were not strong enough to include discussions of sexual behaviors.

\section{Training of Case Managers}

Case managers received virtually no training regarding information on sexually transmitted diseases. There was a centralized orientation for all new case managers provided by the county training program. As a part of the orientation training, new case managers were given some basic information on sexually transmitted diseases. This training program also sponsors ongoing training for the public mental health system. Although they may offer a session on this topic during a particular year, attendance at these sessions is voluntary. Also, since this particular community mental health center was part of a hospital, all staff were required to take Occupational Safety and Health Agency (OSHA) training every year. One section of this computerized training was on standard precautions, including safety and handling of bodily fluids and related apparatus. Other than these trainings, there were no other specialized educational requirements or opportunities regarding sexually transmitted diseases. One case manager volunteered at an agency that did educational training in HIV prevention and she reported training some of her consumers. She also reported being asked questions by other case managers about HIV prevention.

\section{Ecological Assessment}

As a part of the RAP, we observed the environment to see if there were any HIV prevention materials available, such as posters on walls, brochures, or other information. There were none. We also asked whether there were condoms available to give to consumers. The responses were very inconsistent. A few thought that the nurse may have condoms, while others did not know and others said none were available at the agency. The nurse indicated that there were a limited number of condoms available at one time but currently there were none.

\section{CONCLUSIONS}

The results of the RAP confirm the findings of the Encandela et al. (2003) study regarding the delivery of HIV prevention education by case managers. Essentially, formalized training on this topic by case managers is extremely rare. Those case management consumers who are perceived to be at high risk of contracting sexually transmitted infections or are already infected might receive some discussion and advice 
on engaging in safe sex practices. Administrators reported greater availability and use of services than did case managers or consumers. Case managers thought there were greater priorities meeting consumers' primary needs for housing and benefits, and ensuring stabilization of their psychiatric symptoms that took precedence over educating their consumers about sexually transmitted infections. What also came through in this assessment was the disconnect between the willingness of consumers and the apparent discomfort of case managers regarding discussions related to sexual health issues. The barriers to addressing HIV prevention lie primarily with the attitudes of the case managers, since the consumers displayed a great deal of openness and willingness to address issues of sexuality and risk behaviors during the focus groups.

Case managers did feel that HIV and general STI prevention education was important for their consumers and did need to occur. However, these case managers did not feel that they were the most appropriate ones to deliver the intervention. Some noted that other types of providers, such as doctors and nurses, were better suited as educators on these topics related to sexual health and other risk behaviors. Several case managers resounded that linkage was chiefly their role with consumers.

Clearly, when this type of education is left to the idiosyncratic discretion of case managers, there are many who could benefit from such preventive measures who will not receive them. The failure to use existing relationships between case managers and mental health consumers to provide education regarding sexual transmitted infections is a missed opportunity for a highly vulnerable population. It is our assertion that the case managerconsumer relationship is a natural locus of intervention for risk reduction education. Further, we believe that case managers can work on the basic needs of consumers and maintain professional and caring relationships, while delivering complete and accurate information on safer sex and risk reduction behaviors. However, care needs to be taken with design of the intervention to ensure that it fits the nature of case management service delivery. Training case managers to implement preventive interventions must address the attitudinal barriers expressed by some case managers.

\section{REFERENCES}

American Psychiatric Association. AIDS Program Office (Sept 1998). Position Statement and Policy Guidelines on Aids and HIV Disease. Washington, D.C..

Arruffo, J., Thompson, R. McDaaniel, J.S., Sacco, J. et al (1996). Training programs for staff. In Cournos, F., Bakalar, N. (eds.) AIDS and People with Severe Mental Illness: A Handbook For Mental Health Professionals. New Haven: Yale University Press.

Beebe, J. (2001). Rapid Assessment Process. Walnut Creek, Altamira Press.

Blank, M.B., Mandell, D.S. Aiken, L.H., Hadley, T.R. (2002). Co-Occurrence of HIV and serious mental illness among Medicaid recipients. Psychiatric Services. Vol 53(7), 868-873.

Brunette, M., Mercer, C., Carlson, C., Rosenberg, S., Lewis, B. (2000). HIV-related services for persons with severe mental illness: Policy and practice in New Hampshire community mental health. Journal of Behavioral Health Services \& Research, 27, 347-353. 
Carmen, E., Brady, S. (1990). AIDS risk and prevention for the chronic mentally ill. Canadian Journal of Psychiatry. 44, 652-657.

Eisenberg, M.M., Blank, M.B. (2004). HIV and Serious Mental Illness: Prevalence and Treatment Issues. Harvard Health Policy Review, Fall.

Encandela, J., Korr, W., Hulton, K., Koeske, G., Klinkenberg, W.D., Otto-Salaj, L, Silvestre, A., Wright, W. (2003). Mental health case management as a locus for HIV prevention: Results from case-manager focus groups. The Journal of Behavioral Health Services \& Research, 30, 418-432.

Grassi, L (1996) Risk of HIV infection in psychiatrically ill patients. AIDS Care, 8, 103116.

Johnson-Masotti, A., Weinhardt, L., Pinkerton, S., Otto-Salaj, L. (2003). Efficacy and cost-effectiveness of the first generation of HIV prevention interventions for people with severe and persistent mental illness. The Journal of Mental Health Policy and Economics, 6, 23-35.

Kelly, J. (1997). HIV risk reduction interventions for persons with severe mental illness. Clinical Psychology Review. 17, 293-309.

Knox, M. (1989). Community health's role in the AIDS crisis. Community Mental Health Journal. 25, 185-196.

McKinnon, K., Cournos. F., Herman, R., Satriano, J., Silver, B., Puello, I. (1999). AIDSrelated services and training in outpatient mental health care: Agencies in New York. Psychiatric Services. 50, 1225-1228.

Otto-Salaj, L., Stevenson, L., Kelly, J. (1998). Implementing cognitive behavioral AIDS/HIV risk reduction group interventions in community mental health settings that serve people with serious mental illness. Psychiatric Rehabilitation Journal. 21, 394-404.

Otto-Salaj, L., Kelly, J., Stevenson, C., et al (2001) Outcomes of a randomized smallgroup HIV prevention intervention trial for people with serious mental illness. Community Mental Health Journal. 37, 123-144.

Rogers, E.M. (1983). Diffusion of Innovations, New York, Free Press.

Rothbard A. B., Metraux S., Blank, M.B. (2003). Cost of Care for Medicaid Recipients With Serious Mental Illness and HIV Infection or AIDS. Psychiatric Services. Vol.54 (9), 1240-1246.

Shernoff, M. (1988) . Integrating safer-sex counseling into social work practice. Social Casework: The Journal of Contemporary Social Work, 69, 334-339.

Sullivan, G., Koegel, P., Kanouse, D., Cournos, F., Mckinnon, K., Young, A., Bean, D. (1999). HIV and people with serous mental illness: The Public sector's role in reducing HIV risk and improving care. Psychiatric Services. 50, 648-652.

Weinhardt, L. Brickham, N., Carey, M. (1999). Sexual coercion among women living with a severe and persistent mental illness: Review of the literature and recommendations for mental health providers. Aggression and Violent Behavior, 4, $307-317$. 
TABLE 1. Summary of Themes from Interviews and Focus Groups

Current HIV Prevention Practices in Case Management

Occurs informally if at all

Discuss safer sex practices with consumers

Individualized by case manager

Individualized by consumer

May or may not happen based on perceived risk factors

Occurs through service linking

Occurs during doctors visits

Perceived Risk Factors among Consumers

Sexually promiscuous

Multiple partners

Male

IV drug abusing

Symptoms of HIV, Other blood borne infections, e.g., lost a lot of weight

Identified as $\mathrm{HIV+}$

Having Hepatitis

Sexually "inappropriate" and acting out

Engaging in prostitution

Having a new girl friend or boyfriend

Perceived Protective Factors

Sexually inactive

Elderly

Female

Barriers to Discussion of Risk

Southeast Asian - sex taboo topic

Poor relationship with consumer

Consumer very paranoid

Cross gender pairing of CM \& consumer

Recommendations for Training of Case Managers

Basic information as part of orientation to CM

Periodic lectures by experts - voluntary attendance

Requirement for standard precautions of handling bodily fluids - OSHA training 